\title{
ENDOPARASITAS INTESTINAIS EM MAMÍFEROS SILVESTRES NOS FRAGMENTOS DE FLORESTA URBANA
}

Aparecida de Fatima Cracco Rodrigues ${ }^{1}$, Maria de Los Angeles Peres Lizama ${ }^{2}$, Isabele Picada Emanuelli ${ }^{2}$, Natália Ueda Yamaguchi ${ }^{2}$, Edneia Aparecida de Souza Paccola ${ }^{2}$

${ }^{1}$ Mestranda em Tecnologias Limpas pelo Centro Universitário de Maringá, Maringá-PR, Brasil

${ }^{2}$ Docentes do Programa de Pós-Graduação em Tecnologias Limpas do Centro

Universitário de Maringá/ICETI - Maringá - PR, Brasil

(edneia.paccola@unicesumar.edu.br)

Recebido em: 08/04/2017 - Aprovado em: 10/06/2017 - Publicado em: 20/06/2017 DOI: 10.18677/EnciBio_2017A110

\begin{abstract}
RESUMO
A ecologia urbana estuda as interações entre plantas, animais e seres humanos perante a urbanização e as consequências do descaso com o meio ambiente. Os mamíferos silvestres são animais de grande importância para sustentabilidade dos fragmentos de floresta e para o controle da disseminação de endoparasitas, portanto estudos sobre esses animais são necessários para preservação de espécies silvestres e para o equilíbrio de infecções parasitárias nesses locais. Esta pesquisa investigou a incidência de cestódeos, em mamíferos silvestres encontrados mortos por atropelamento, ao redor de um fragmento de floresta próximo a uma área urbana no noroeste do Paraná. Foi aplicado o método de sedimentação espontânea nas amostras fecais das seguintes espécies: Tamandua tetradactyla (dois tamanduás), Didelphis albiventris (um gambá), Sapajus nigritus (dois macacos prego) e Cerdocyon thous (um cachorro do mato). Os resultados mostraram a presença de exemplares de Hymenolepis nana no Didelphis albiventris (gambá) e Hymenolepis diminuta no Tamandua tetradactyla (tamanduá); estes cestóideos apresentaram proglótides jovens e proglótides grávidos, sendo possível observar claramente os ovos com aspectos transparentes, incolores e viáveis. Foi evidenciada a presença de Hymenolepis diminuta em Tamandua tetradactyla, porém, na literatura existem poucos relatos sobre a presença deste endoparasita nesta espécie de mamífero. A preservação destes mamíferos silvestres nestes fragmentos de floresta consiste em um grande desafio, pois além do espaço ser reduzido e quase sempre deficiente em alimentação propícia à dieta desses animais, em cenários como esse os endoparasitas são facilmente disseminados causando desequilíbrio ambiental nestes fragmentos de floresta urbana.
\end{abstract}

PALAVRAS-CHAVE: Desequilíbrio ambiental, Mamíferos, Parasitas Intestinais. 


\title{
INTESTINAL ENDOPARASITES IN WILD MAMMALS IN URBAN FOREST FRAGMENTS
}

\begin{abstract}
Urban ecology studies the interactions between plants, animals and humans in the face of urbanization and the consequences of environmental neglect. Wild mammals are animals of great importance for the sustainability of forest fragments and to control the spread of endoparasites, studies on these animals are necessary for the preservation of wild species and for the balance of parasitic infections at these sites. This research investigated the incidence of cestodes in wild mammals found dead by trampling around a Forest Fragment near the urban area in the northwest of Paraná. The spontaneous sedimentation method was applied to fecal samples of the following species: Tamandua tetradactyla (two anteaters), Didelphis albiventris (a possum), Sapajus nigritus (two monkeys nail) and Cerdocyon thous (a bush dog). The results showed the presence of Hymenolepis nana in Didelphis albiventris (possum) and Hymenolepis diminuta in Tamandua tetradactyla (tamanduá). These cestodes had young proglottids and pregnant proglottids, and it was possible to observe clearly the eggs with transparent, colorless and viable appearance. It was evidenced the presence of Hymenolepis diminuta in Tamandua tetradactyla, in spite in the literature there are few reports about the presence of this endoparasite in this species of mammal. The preservation of these wild mammals in these forest fragments is a great challenge because, in addition to the space being reduced and almost always deficient in food suitable for the diet of these animals, scenarios such as these endoparasites are easily disseminated causing environmental imbalance in these fragments of urban forest.
\end{abstract}

KEYWORDS: Environmental Imbalance, Mammals, Intestinal Parasites,

\section{INTRODUÇÃO}

A ecologia urbana procura entender os sistemas naturais dentro das áreas urbanas, como as interações de plantas, animais e de seres humanos nesses locais, e visa analisar até que ponto esses recursos são afetados pela poluição, urbanização e outras formas de pressão e as suas consequências para o futuro da humanidade. A conscientização das pessoas sobre a ecologia urbana e a sustentabilidade pode levar a um equilíbrio pleno entre o progresso e a preservação do meio ambiente (ALMEIDA, 2010). A ocupação do solo realizada pelo homem, em prol da urbanização e da produção agrícola, transformou áreas contínuas de florestas em fragmentos isolados de diversos tamanhos, afetando assim a biodiversidade. Pois com a diminuição dos hábitats e recursos alimentares, houve uma redução do número de animais silvestres destes fragmentos, avolumando a lista de extinção (GALETTI, 2010; CARDOSO, 2016; PADILIA, 2016).

O Brasil conta com o registro de aproximadamente 701 espécies de mamíferos, sendo a Mata Atlântica o segundo bioma brasileiro em termos de riqueza de espécies, com 298 reconhecidas, sendo que 90 destas são exclusivas do bioma. Um total de 110 espécies de mamíferos brasileiros consta na lista de espécies ameaçadas de extinção (ICMBIO, 2014). No Paraná, há, aproximadamente, 180 espécies de mamíferos, sendo 30 destas ameaçadas de extinção (ICMBIO, 2012). Na lista de mamíferos "criticamente ameaçados" (CR), encontra-se a Panthera onca (onça pintada), Pteronura brasiliensis (ariranha), Speothos venaticus, (cachorro-do- 
mato-vinagre), Tayassu pecari (queixada). Na categoria "em perigo" (EN), a Cuniculus (paca) e a Tapirus terrestris (anta). Entre as espécies vulneráveis da lista (VU), está o Alouatta guariba (bugio-ruivo), Chiroderma doriae, Chrotopterus auritus, (morcegos), Leopardus pardalis (jaguatirica), Leopardus tigrinus (gato-do-matopequeno), Leopardus wiedii (gato-maracajá), Lontra longicaudis (Iontra), Mazama nana (veado-mão-curta), Pecari tajacu (cateto), a Puma concolor (onça parda) e Sylvilagus brasiliensis (coelho-do-mato) (PARANÁ, 2007; DO NASCIMENTO, 2011; ICMBIO, 2014).

O fato de várias espécies de mamíferos silvestres estarem em risco de extinção se dá por vários motivos, um deles é o auto índice de atropelamento desses animais, que ocorrem pela carência de sinalização preventiva e a falta de mecanismos de transposição dos animais de um fragmento para outro, forçando os animais a se ariscarem ao atravessar as vias automobilísticas (ICMBIO, 2012; STEIL, 2016; DEFFACI, 2016).

Essas interferências no habitat natural dos mamíferos silvestres favorecem a disseminação de parasitos que podem representar um problema no manejo e recuperação de espécies silvestres, como os mamíferos. Um grande número de parasitas tem esses animais como hospedeiro, podendo prejudicar o seu desenvolvimento e até causar a morte, dependendo do estado nutricional e das condições fisiológicas que se encontra o animal parasitado (CARDOSO, 2016). Os cestódeos são endoparasitas que habitam o sistema digestório da maioria dos mamíferos silvestres, domésticos e também do homem, são pertencentes ao Filo Platyhelminthes, conhecidos como Hymenolepis sp (tênias). Os parasitas adultos não possuem sistema digestório por isso desenvolvem-se no intestino do hospedeiro (DA FONSECA, 2012; NEVES, 2016).

Em relação à anatomia dos Platyhelminthes, (FRANSOZO \& NEGREIROSFRANSOZO, 2016) eles apresentam simetria bilateral, extremidade anterior com órgãos sensitivos, de fixação e uma extremidade posterior, ausência do exoesqueleto ou endoesqueleto; são achatados, o dorso, ventralmente, sem celoma, com ou sem tubo digestivo, sem ânus, sem aparelho respiratório, sistema excretor tipo protonefrídico, com tecido conjuntivo enchendo os espaços entre os órgãos (NEVES, 2016). PAVANELLI et al. (2015) explica que os cestoides podem medir de $5 \mathrm{~mm}$ até $10 \mathrm{~m}$ de comprimento, morfologicamente, são constituídos de estróbilo, colo, e escólex. O escólex possui estruturas de fixação chamadas de ventosas ou ganchos. As proglótides maduras formam os segmentos dos cestódeos, é nelas que os ovos se formam e depois são eliminados através das fezes do hospedeiro.

As infecções parasitárias são intimamente relacionadas aos alimentos e hábitos dos animais e quando presentes nos intestinos absorvem quantidades significativas de nutrientes que seriam absorvidos pelo organismo do animal. (ZACHARY, 2002). Esta pesquisa investigou a incidência de cestódeos, endoparasitas intestinais em mamíferos silvestres visando obter conhecimento sobre estes animais em um fragmento de floresta reduzida ao redor de uma área urbana no noroeste do Paraná.

\section{MATERIAL E MÉTODOS}

A pesquisa foi realizada em um fragmento de floresta estacional semidecidual (Reserva Biológica) localizado na região noroeste do Estado do Paraná, criada em 2006. Sua localização é determinada pelos pontos de coordenadas geográficas $23^{\circ}$

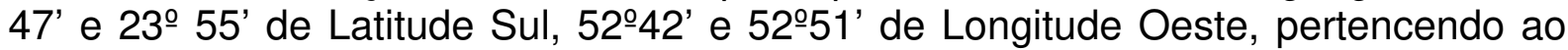
bioma Mata Atlântica e ao Terceiro Planalto Paranaense ou Planalto de 
Guarapuava. Sua área territorial é de 8.716 hectares (ICMBIO 2012; CARRANO, 2013).

Esta pesquisa foi submetida ao Comitê de Ética em Pesquisa, sob o parecer: 1.726.287, para a investigação da incidência de cestódeos, endoparasitas intestinais, utilizou-se amostras de fezes retiradas diretamente do intestino de cinco mamíferos silvestres encontrados mortos, por atropelamento ao redor da reserva biológica. Sendo eles representantes das seguintes espécies; Tamandua tetradactyla (dois tamanduás), Didelphis albiventris (um gambá), Sapajus nigritus (dois macacos prego) e Cerdocyon thous (um cachorro do mato), todos apresentavam idade adulta e intestino conservado, apesar das carcaças apresentarem sinais claros de atropelamento, como ossos do crânio e ossos de membros anteriores fraturados. Os demais animais apresentaram coágulos de sangue indicando uma possível causa da morte, por hemorragia. Os intestinos dos animais foram então retirados no laboratório de zoologia em uma Instituição de Ensino Superior, resfriados em sacos plásticos incolores e identificados.

Para verificação da presença de ovos de cestódeos nas amostras fecais coletadas foi aplicado o método de sedimentação espontânea de HOFFMAN et al., (1934), metodologia simples que identifica parasitas intestinais (DE CARLI, 2007). Segundo URQUHART (1998) este método permite a remoção do material particulado, sendo possível identificar parasitas habitantes do tubo digestório por produzirem ovos, larvas ou cistos que geralmente são encontrados nas fezes contidas nos intestinos com a presença de parasitas adultos. Para este método utilizou-se $100 \mathrm{~mL}$ de água destilada e $10 \mathrm{~g}$ de fezes de cada animal analisado. As amostras descansaram durante 2 horas em cálice de $200 \mathrm{~mL}$. Posteriormente foi colocada uma gota da amostra em lâmina de $24 \times 24 \mathrm{~mm}$ e adicionada uma gota de iodo inorgânico a 5\%.

A observação foi realizada em microscópio óptico, foram confeccionadas 15 lâminas de cada amostra do sedimento para a análise e identificação das estruturas morfológicas dos ovos, tais como características, os ornamentos da casca e formação embrionária. Para a investigação da presença de cestódeos adultos nas amostras fecais, aplicou-se exame direto das fezes, utilizado cinco gramas de porção pastosa, retiradas da porção inicial, mediana e final dos intestinos. As fezes foram colocadas em placas Petri e observadas com o microscópio estereoscópico, diluindo as fezes quando necessário em água destilada, totalizando três repetições cada porção intestinal analisada (CIMERMAN \& CIMERMAN, 2002).

\section{RESULTADOS E DISCUSSÃO}

Das amostras de fezes analisadas dos mamíferos silvestres, o Tamandua tetradactyla (Tamanduá) apresentou o endoparasita Hymenolepis diminuta (tênia) e - Didelphis albiventhis (Gambá) com o Hymenolepis nana. Nos demais mamíferos analisados não foram encontrados cestódeos no intestino através dos métodos empregados para este estudo (quadro 1). CARDOSO (2016) destaca que os mamíferos silvestres são reservatórios desses parasitas, que por sua vez, através de ovos viáveis possuem grande capacidade de disseminação. Uma das causas da distribuição de parasitas está associada a fatores ambientais como: mudanças em parâmetros físicos do ambiente, habitats reduzidos e diferenças na susceptibilidade do hospedeiro à infecção. 
QUADRO 1. Resultado da análise fecal realizada no intestino das carcaças dos mamíferos silvestres.

\begin{tabular}{|l|l|c|}
\hline Nome científico & Nome popular & Endoparasita \\
\hline Tamandua tetradactyla & Tamanduá & Hymenolepis diminuta \\
\hline Tamandua tetradactyla & Tamanduá & - \\
\hline Didelphis albiventhis & Gambá & Hymenolepis nana \\
\hline Sapajus nigritus & Macaco & - \\
\hline Sapajus nigritus & Macaco & - \\
\hline Cerdocyon thous & Cachorro do mato & - \\
\hline
\end{tabular}

Portanto o habitat dos mamíferos silvestres deve ser preservado uma vez que esses animais são importantes mantedores do equilíbrio no ecossistema (GALETTI, 2010); os mamíferos carnívoros, por exemplo, são reguladores de populações de espécies herbívoras, que se alimentam de vegetais, ou seja, a extinção dos mamíferos silvestres pode significar o colapso do ambiente natural em médio ou longo prazo (REIS, 2006). É evidente o declínio de espécies, em nível regional e global, principalmente, pela perda acelerada de habitats, ameaçando a manutenção de biomas inteiros (VILELA, 2016).

O cestódeo encontrado no Tamandua tetradactyla (tamanduá) classificado como Hymenolepis diminuta (Figura 1A) apresentou aproximadamente 30 centímetros de comprimento, proglótides grávidos (Figura 1B) e vários ovos de Hymenolepis diminuta dispersos no intestino do animal, os ovos apresentavam aspectos transparentes, incolores e viáveis.
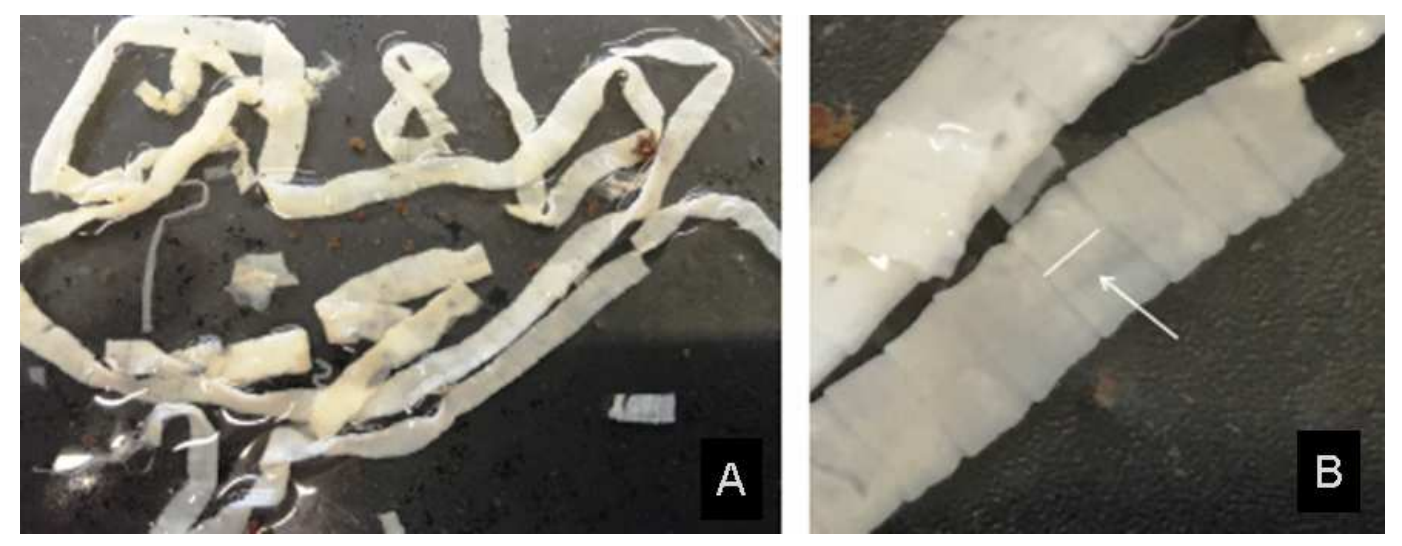

FIGURA 1. Hymenolepis diminuta adulto apresentando aproximadamente $30 \mathrm{~cm}(\mathrm{~A})$, observada em microscópio estereoscópico na objetiva de $4 \mathrm{X}$ e proglótides grávidas (B) na ponta da seta observado nas fezes do Tamandua tetradactyla. Fonte: autores

Para NEVES (2016), os ovos são uma das formas de transmissão desses cestódeos, que ao serem ingeridos por meio de água e alimentos, instalam-se no intestino dos mamíferos e também em outros animais, silvestres ou domésticos. Outra forma de transmissão é através do cisticerco da Hymenolepis diminuta que são encontradas em alguns Coleopteras (carunchos), Siphonaptera (pulgas) e outros insetos que quando ingeridos pelos seus predadores como o Tamandua tetradactyla (tamanduá mirim), completam o seu ciclo, passando à forma adulta no intestino do animal; esta forma de transmissão pode parasitar a maioria dos 
mamíferos silvestres (REYES, 2015; PAVANELLI et al., 2015; MANSUR, 2016; LOPES, 2016). A presença desses parasitas no intestino dos mamíferos silvestres pode interferir na absorção intestinal, uma vez que quantidades significativas dos nutrientes são utilizadas pelo parasita no seu ciclo de vida, segundo ZACHARY (2002).

No Didelphis albiventris (gambá) verificou-se um exemplar de Hymenolepis nana adulto com proglótides grávidas (Figura 2A) com aproximadamente 4,5 cm, um dos menores cestódeos do Filo Platyhelminthes, apresentando escólex com quatro ventosas (Figura 2B). A Hymenolepis nana não requer hospedeiro intermediário, mas carunchos e pulgas podem servir como tal, possuindo de 10 a $45 \mathrm{~mm}$ de comprimento e até 200 proglótides (PAVANELLI et al., 2015; NEVES, 2016).
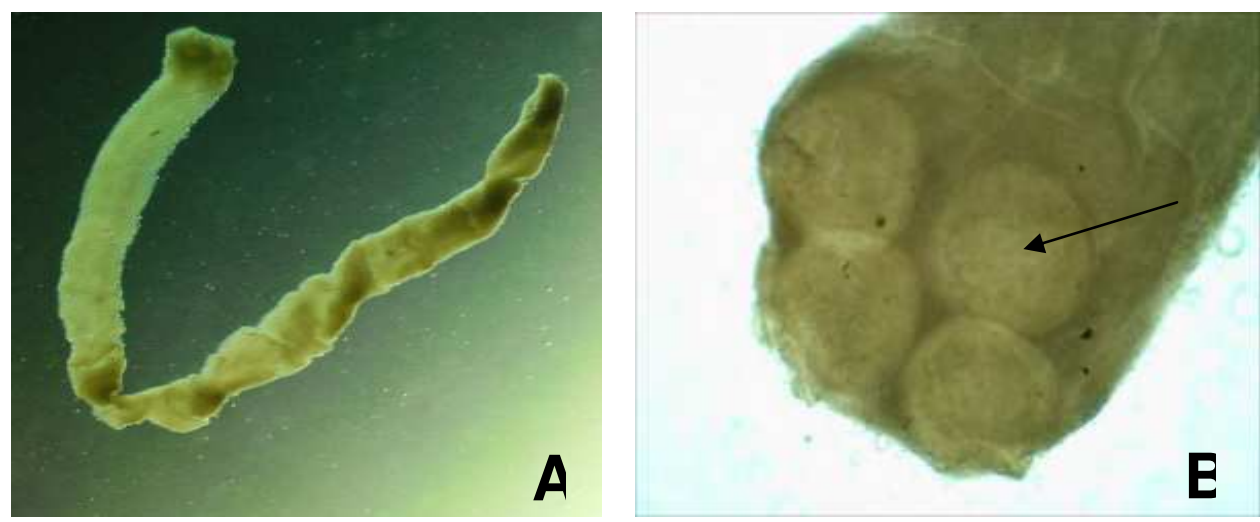

FIGURA 2. Hymenolepis nana adulta observada em microscópio óptico na objetiva de 40x (A) e escólex de Hymenolepis nana com quatro ventosas (B) (seta), na objetiva 100x. Fonte: Autores.

Dentro dos proglótides grávidos existe o útero, que gradualmente se torna um saco ramificado repleto de milhares de ovos. Podendo ocorrer autofertilização da proglótide, com espermatozóides e óvulos produzidos pelos órgãos genitais do segmento; outras vezes pode ocorrer fertilização de um segmento por espermatozóides produzidos em outros segmentos do mesmo cestódeo (AMIRMOHAMMADI et al., 2014; NEVES, 2016; FRANSOZO \& NEGREIROSFRANSOZO, 2016).

O surgimento de novas doenças relacionadas com o parasitismo ou recrudescimento de outras já controladas, apresentam forte relação com as alterações na paisagem, decorrentes de intervenções humanas (CARDOSO, 2016), pois em áreas compostas por florestas fragmentadas o espaço é limitado e os cestódeos como Hymenolepis diminuta e Hymenolepis nana podem facilmente explorar um número maior de hospedeiros, uma vez que seus ovos são liberados pelas fezes dos animais silvestres parasitados, sobre o solo apresentando-se resistente, com capacidade de contaminação. Sendo assim os cestódeos podem vir a ser mais um agravante da situação atual na qual se encontram a maioria dos mamíferos silvestres que vivem em fragmentos de florestas no noroeste do Paraná.

A situação nutricional desses animais se agrava ainda mais, uma vez que nos fragmentos de floresta segundo TROMBULAK (2004) há uma diminuição dos recursos alimentares. De forma geral, a fragmentação destas florestas resultou na diminuição de espécies vegetais e animais, comprometendo a biodiversidade e 
deixando clara a importância da preservação desses locais, pois desempenham um papel chave para a manutenção e equilíbrio do ecossistema (GALETTI \& DIRZO, 2013; MARTINI \& BIONDI, 2015; MENDES, 2016).

Muitas dessas áreas estão inseridas em perímetro urbano, apresentando em seu estado original uma alteração ainda maior, provocada pelo avanço populacional (RUBIRA, 2016). Na concepção de MACIEL (2015) outros fatores que também ameaçam a sobrevivência dos animais silvestres nestes resquícios de florestas são os atropelamentos e o contato de animais domésticos com capacidade de predação.

\section{CONCLUSÃO}

A escassez de informações que abordam a ocorrência de endoparasitas intestinas em animais silvestres como, por exemplo, a Hymenolepis diminuta e a Hymenolepis nana, levou a concluir-se que é fundamental o incentivo de pesquisas que cooperem para o enriquecimento do conhecimento científico. Visto que, a preservação dos mamíferos silvestres nos fragmentos de florestas, compostas por habitats reduzidos e deficientes de alimentação (propícia à dieta desses animais), depende do conhecimento e de ações concretas que visam controlar o desequilíbrio ambiental.

\section{REFERÊNCIAS}

ALMEIDA, L. C. S. A importância da ecologia urbana para o futuro da humanidade. In: Âmbito Jurídico, Rio Grande, XIII, n. 73, fev. 2010. Disponível em: $<$ http://www.ambitojuridico.com.br/site/index.php?n_link=revista_artigos_leitura\&artig o_id=7242>. Acesso em novembro. 2016.

AMIRMOHAMMADI, M., KHAJOENIA, S., BAHMANI, M., RAFIEIAN-KOPAEI, M., EFTEKHARI, Z., QORBANI, M. In vivo evaluation of antiparasitic effects of Artemisia abrotanum and Salvia officinalis extracts on Syphacia obvelata, Aspiculoris tetrapetra and Hymenolepis nana parasites. Asian Pacific Journal of Tropical Disease, v. 4, p.250-254, 2014. DOI: http://doi.org/10.1016/S2222-1808(14)60449-7

CARDOSO, T. S.; SIMÕES, R.O.; LUQUE; J. L.; MALDONADO, A.; GENTILE, R.; The influence of habitat fragmentation on helminth communities in rodent populations from a Brazilian Mountain Atlantic Forest. Journal of Helminthology, v. 90, n. 4, p. 460-468, 2016. DOI: 10.1017/S0022149X15000589.

CIMERMAN, B.; CIMERMAN, S. Parasitologia humana e seus fundamentos gerais. São Paulo: Editora Atheneu, 2002.

CORRÊA, S.H.R.; PASSOS, E.C. Wild animals and public health. In: Fowler, ME Cubas, ZS. Biology, medicine, and surgery of South American wild animals. Ames: lowa University Press, p. 493-499, 2001.

DA FONSECA, M. C. G. Trypanorhyncha cestodes of hygienic-sanitary importance infecting flounders Paralichthys patagonicus Jordan, 1889 and Xystreurys rasile (Jordan, 1891) of the Neotropical region, Brazil. Parasitology Research, v. 111, n. 2, p. 865-874. DOI :10.1007/s00436-012-2912. 
DE CARLI, G. A. Parasitologia clínica: Seleção de métodos e técnicas de laboratório para diagnóstico das parasitoses humanas. 2 ed. Rio de Janeiro: Atheneu, 2007.

DE OliveiRA, L. P. AGUIAR, D, MARGARIDO, T. C. C., \& PACHALY, J. R. Caracterização faunística de mamíferos de médio e grande porte de um fragmento florestal do noroeste do estado do Paraná, Brasil. Arquivos de Ciências Veterinárias e Zoologia da UNIPAR, v. 15, n. 2, p. 109-114, 2013.

DEFFACI, A. C.; DA SILVA, V. P.; HARTMANN, M. T.; HARTMANN, P. A diversidade de aves, mamíferos e répteis atropelados em região de floresta subtropical no sul do Brasil. Ciência e Natura, v. 38, n. 3, p. 1205-1216, 2016. DOI: 10.5902/2179460X22020/

DO NASCIMENTO, J. L; CAMPOS, I. B. Atlas da fauna brasileira ameaçada de extinção em unidades de conservação federais. Brasília: Instituto Chico Mendes de Conservação da Biodiversidade, p.186-210 2011. DOI: org/10.1590/S16760603 2010000400006.

GALETTI, M.; DIRZO, R. Ecological and evolutionary consequences of living in a defaunated world. Biological Conservation. v. 163, p. 1-6, 2013. DOI: https:doi.org/10.1016/j.biocon.2013.04.020

GALETTI, M.; PARDINI, R., DUARTE, J. M. B., DA SILVA, V. M. F., ROSSI, A., PERES, C. A. Forest legislative changes and their impacts on mammal ecology and diversity in Brazil. Biota Neotropica, v. 10, n. 4, p. 47-52, 2010. DOI: http://dx.doi.org/10.1590/S1676-06032010000400006

HOFFMANN, W. A.; PONS, J. A.; JANER, J. L. The Sedimentation-Concentration Method in Schistosomiasis mansonl. Puerto Rico Journal of Public Health and Tropical Medicine, v. 9, n. 3, 1934.

IBAMA- Instituto Brasileiro do Meio Ambiente e dos Recursos Naturais Renováveis. Fauna,1993. Disponível em http://www.ibama.gov.br/fauna/criadores.php. Acesso em agosto de 2016.

ICMBio - Instituto Chico Mendes de Conservação da Biodiversidade, Plano de Manejo Reserva Biológica das Perobas, 2012. Disponível em: < file://C:/users/rootti/downloads/rebio\%20das\%20perobas\%20\%20final2\%20(1).

Acesso em outubro de 2016.

ICMBio - Instituto Chico Mendes de Conservação da Biodiversidade, 2014. Disponível em: < http://www.icmbio.gov.br/portal/especies-ameacadas-destaque >. Acesso em outubro de 2016.

LOPES, F., REYES, J. L., LEUNG, G., MANCINI, N., WANG, A., \& MCKAY, D. Extracts of the tapeworm, Hymenolepis diminuta, recruit CCR2+ PDL1+ Myeloid Cells with the capacity to inhibit dextran sodium sulphate induced-colitis. The FASEB Journal, v. 30, n. 1 Supplement, p. 57.1-57.1, 2016. DOI: 10.1096/fj.1530-6860 
MACIEL, L; MACIEL, K. P. W. A. Levantamento preliminar de mamíferos silvestres em uma área de Floresta Ombrófila Mista na região de Porto Vitória-PR. Revista Eletrônica de Biologia, v. 8, n. 1, p. 13-28, 2015. ISSN 1983-7682

MANSUR, F., LUOGA, W., BUTTLE, D. J., DUCE, I. R., LOWE, A., \& BEHNKE, J. M. The anthelmintic efficacy of natural plant cysteine proteinases against the rat tapeworm Hymenolepis diminuta in vivo. Journal of Helminthology, v. 90, n. 03, p. 284-293, 2016. DOI: https://doi.org/10.1017/S0022149X1500012

MARTINI, A; BIONDI, D. Microclimate and Thermal Comfort of an Urban Forest Fragment in Curitiba, Paraná State, Brazil. Floresta e Ambiente, v. 22, n. 2, p. 182193, 2015. DOI: http://dx.doi.org/10.1590/2179-8087.082114

MENDES, F. H., DE SOUZA PETEAN, F. C., POLIZEL, J. L., \& DA SILVA FILHO, D. F. Avaliação da fragmentação da cobertura arbórea de Maringá/PR utilizando geotecnologias. Scientia Plena. v. 12, n. $9,2016 . \quad$ DOI: 10.14808/sci.plena.2016.090201

MIRANDA, J. M. D; RIOS, R. F. M.; DE CAMARGO PASSOS, F. Contribuição ao conhecimento dos mamíferos dos Campos de Palmas, Paraná, Brasil. Biotemas, v. 21, n. 2, p. 97-103, 2008. DOI: http://dx.doi.org/10.5007/2175-7925.2008v21n2p97

NEVES, D. P.; MELO A. L. LINARDI P. M.; ALMEIDA R. W. VITOR. Parasitologia Humana. 13a ed. São Paulo: editora Atheneu, 2016.

PADILHA, R.; PORTUGAL, J. L., DOS SANTOS, A. V., PEREIRA, S. V.; DO CARMO, T. V. B. Proposição de Modelo de Corredores Ecológicos com Base no Sistema de Informações Geográficas na Região de Suape, Pernambuco, Revista Brasileira de Geografia Física, v. 9, n. 1, p. 079-090, 2016. ISSN 1984-2295

PARANÁ, SECRETARIA DO ESTADO DO MEIO AMBIENTE. Fauna do Paraná em Extinção, obra extraída do livro Lista vermelha dos animais ameaçados de extinção no Estado do Paraná. Curitiba: SEMA/GTZ, 2007. Disponível em http://www.meioambiente.pr.gov.br/arquivos/File/cobf/livro_fauna_extincao.pdf. Acesso outubro de 2016.

PAVANELLI, G. C.; EIRAS J.C. YAMAGUCHI M.U.; TAKEMOTO, R.M. Zoonoses Humanas Transmissíveis por Peixes. Maringá- PR. $1^{\circ}$ edição. V.1. Editora: Unicesumar, p. 145, 2015.

REIS, N. R. P. PEDRO, A. L.; LIMA, W. A. Mamíferos do Brasil. MAM. 2006. p. 437

REYES, J. L., WANG, A., FERNANDO, M. R., GRAEPEL, R., LEUNG, G., VAN ROOIJEN, N., MCKAY, D. M. Splenic B cells from Hymenolepis diminuta-infected mice ameliorate colitis independent of $T$ cells and via cooperation with macrophages. The Journal of Immunology, v. 194, n. 1, p. 364-378, 2015. DOI: https://doi.org/10.4049/jimmunol.1400738

RUBIRA, F. G. Análise multitemporal da expansão urbana de Maringá-PR durante o período de 1947 a 2014 envolvendo o Parque Municipal do Cinquentenário e as 
principais áreas verdes do município/Multitemporal. Caderno de Geografia, v. 26, n. 46, p. 333-361, 2016. ISSN 2318-2962

SILVA, J. R. R.; ORTÊNCIO-FILHO, H. Dípteros ectoparasitas (Insecta, Diptera) em morcegos (Chiroptera, Mammalia) na Reserva Biológica das Perobas Paraná, Brasil. Iheringia, Série Zoologia, v. 101, n. 3, p. 220-224, 2011. DOl: http://dx.doi.org/10.1590/S0073-47212011000200009

STEIL, L.; DÜPONT, A.; LOBO, E. A. Levantamento da fauna silvestre atropelada na BR 290 (km 210 a 214), município de pântano grande, RS, Brasil. Caderno de Pesquisa, v. 28, n. 1, p. 13-23, 2016. DOI: http://dx.doi.org/10.17058/cp.v28i1.7855

TROMBULAK, S. C., K. S. OMLAND, J. A. ROBINSON, J. J. LUSK, T. L. FLEISCHNER, G. BROWN, Y M. DOMROESE. Principles of Conservation Biology. v. 18, n. 5, Out, 2004. DOI: 10.1111/j.1523-1739.2004.01851.x

URQUHART, M. G; ARMOUR, J; DUNCAN, L. J; DUNN, M. A; JENNINGS, W. F. Parasitologia Veterinária. $2^{\circ}$ edição p. 239 a 250. Guanabara Koogan. São Paulo 1998.

VILELA, D. A. R.; BARRETO, C.; OLIVEIRA, D. M. P. Principais ameaças e medidas de salvaguarda aos animais silvestres. MPMG Jurídico: Revista do Ministério Público do Estado de Minas Gerais, 2016. Disponível em: https://aplicacao. mpmg.mp.br/xmlui/bitstream/handle/123456789/1279/Principais\%20amea\%C3\%A7a s\%20e\%20medidas\%20de\%20salvaguarda.pdf?sequence=1. Acesso em dezembro 2016. 